\title{
Norman Kreitman
}

\author{
In conversation with David Tait
}

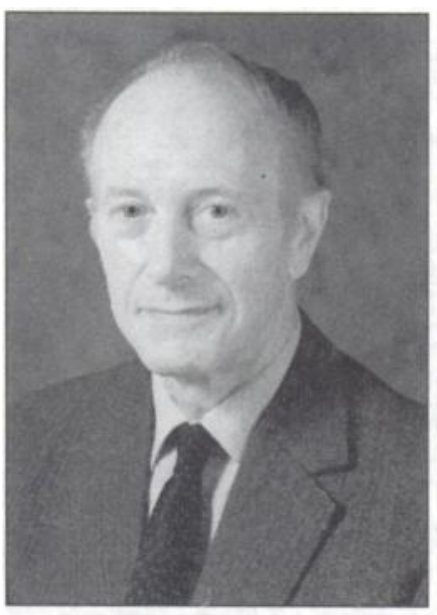

Norman Krettman

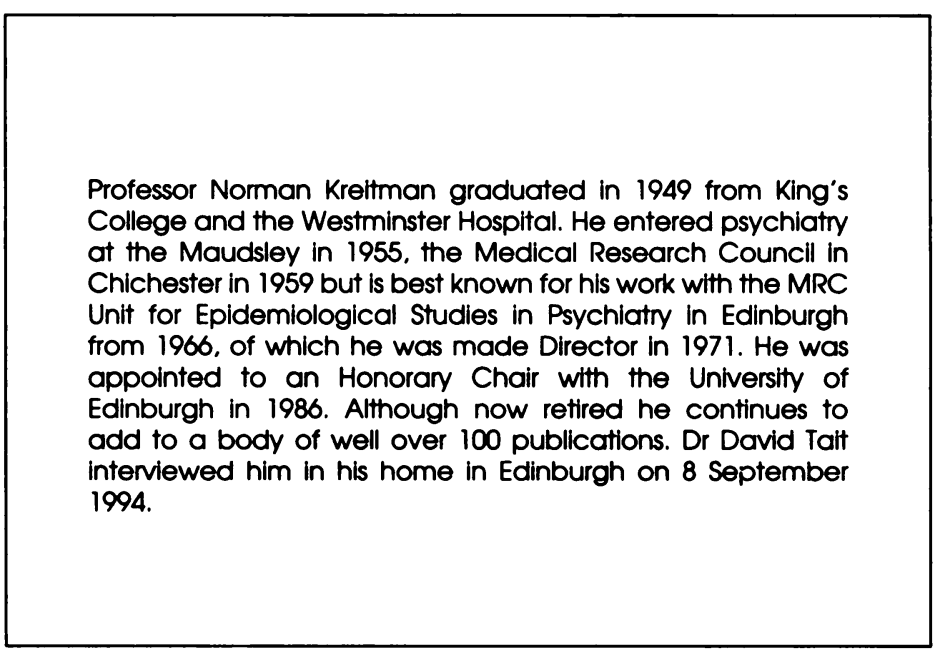

It's almost $\mathbf{3 0}$ years since you came to Scotland, can we claim you as a naturalised Scot?

Yes, I think so by now. I know this must be the case because at Murrayfield I cheer Scotland when they are playing against England!

\section{Yet Kreitman isn't an old Scottish name?}

No, indeed it isn't. My grandparents on both sides were poor immigrants from Eastern Europe who settled in London around the beginning of the century. The subsequent evolution of the family was fairly typical; they were all hard-working, and about the time my generation arrived we were beginning to enter the professions. I was the first doctor except for one cousin.

\section{So what led you to study medicine?}

At school I had all sorts of interests, including literature, but perhaps the strongest was in biology and I knew I wanted to do something more or less scientific or more or less biological. Medicine seemed the logical choice, and led on to a training at the Westminster Hospital.
I am always intrigued by unusual things in people's Isle of Wight in the early '50s, in part at a large tuberculosis hospital. This is quite foreign to my generation of doctors. What are your recollections of that time?

My period in the Isle of Wight was partly spent in general medicine, quite an exciting post because the National Health Service had just been introduced and the changes we were able to make were dramatic and very heartwarming, but most of my time there was spent in a fairly sizeable sanatorium. which was still common although it was beginning to become less so. Life in a sanatorium had a peculiar aura of its own, a whole ethos which in many ways was very attractive if you liked a fairly leisurely pace. I might have stayed in tuberculosis for ever I suppose but I was advised by a very wise my lifetime. I did however apply for and obtained a Fellowship in Pulmonary Physiology, at the Forlanini Institute in Rome, which proved to be a very enjoyable year. It introduced me to a completely different curricula vitae and I see you spent 18 months in the Tuberculosis in those days was a disorder Superintendent that the subject wouldn't last 
style of running a hospital, and of course there was always the background of life in Rome when you were 24 , single and not too busy.

Let us have a further diversion into that time in Rome.

The Institute attracted a substantial number of overseas fellows, and we spent the mornings going on ward rounds which were always rather dramatic occasions.

I recall that the Director, who invariably participated, would never use a stethoscope he always applied his ear directly to the chest and then would mark with a skin pencil what he thought was going on inside the thorax. Only then were the X-rays produced. He was invariably right to within a whisker. The standard of radiology, incidentally, was superb (and of anaesthesia, appalling). After the round you went to one of the research departments, where not much happened but where the atmosphere was always cordial. In the afternoon the other junior staff went off to earn their living, as they were virtually unpaid.

It was six years from qualification when you entered psychiatry. How did that come about?

I had taken a post as registrar in a general hospital, Metropolitan Hospital, when I returned to London. This involved working for five physicians, four of whom I had readily identified but the fifth remained elusive. It was only by chance that late one evening going home through the out-patient department I noticed that all the benches had been moved and a series of mattresses put down on which a number of semi-conscious forms were stretched. Enquiry showed that these were patients having out-patient ECT and that the person running the clinic was the elusive fifth consultant, Dr Edward Larkin, who was the psychiatrist to the hospital. I introduced myself to him, and enjoyed the subsequent contact with him thoughout my remaining time there. He was very much an eclectic, very approachable and always interested in discussing - usually over a glass of beer questions of psychopathology if I cared to raise them, which I did. Subsequently I wrote to Dr David Davies, the Dean at the Maudsley Hospital, simply asking how one set about a career in psychiatry. He kindly invited me to meet him and we talked around the possibilities. He then suggested that I might meet one of the other consultants. This I did and we spent a pleasant hour discussing the state of the West End theatre. To my surprise I subsequently received a letter saying that my application for admission had been accepted and would I please start in two weeks' time!

What particular influences do you remember from your four years at the Maudsley?

It was an exciting if somewhat stressful period. A number of towering figures were on the staff at the time. Among the many who come to mind were people like Elliot Slater and Erwin Stengel, two completely different characters, both of whom I liked. Then there was the experience of working with such luminaries as Felix Post for whom I had, and retain, considerable admiration. There was also Foulkes, who was one of the pioneers of group psychotherapy, and a psychoanalyst called Willie Hoffer whose registrar I was for nearly a year. He was one of the kindest men I ever met and I imagine was the only psychoanalyst in the world who sent his patients chickens at Christmas.

But of course the dominating influence at the Maudsley at that time was Sir Aubrey Lewis. I was never on his firm but I did attend virtually all the famous Monday morning case conferences at which he presided. The custom was for the case to be presented by the registrar in not more than 25 minutes and if you failed to appreciate some recondite detail you were duly humiliated, mercilessly, in front of the whole hospital. The discussion that followed was always confined to the consultants and sometimes ended in a veritable ding-dong of rival viewpoints from which one could enjoy considerable satisfaction and entertainment as well as instruction. All the same Aubrey Lewis did succeed in imposing his own style of orthodoxy on most of the juniors. It was only after leaving the Maudsley that one acquired any sense of freedom in what one might think about psychiatric matters - the sensation was rather as though an elephant had got off one's back even if one hadn't been fully aware of his presence before. Even after leaving, though, Lewis' critical approach has remained lodged like a splinter in my professional superego, as was the case I suppose for everyone exposed to the Maudsley influence of the time. Of course, he had his limitations, but his insistence on your doing your library homework and on clarity of reasoning were very positive influences. 
So you found that freedom by joining the Medical Research Council in its Clinical Psychiatry Research Unit in Graylingwell Hospital in Chichester where you worked for the next six years?

Yes, Graylingwell was interesting in two ways. First, it was one of the earliest centres to embrace the new concept of community care and to develop an extensive system of outpatient and domiciliary work which really did seem to work. The second was that it housed an MRC unit which was not located in a university centre. It was run by Peter Sainsbury of whom I have nothing but the kindest recollections. I learnt a great deal from him. What impressed me chiefly was his genius for simplicity. He had a way of seeing to the heart of a complex issue, resolving it into its essentials and then elegantly designing a project which would answer these simple but fundamental questions.

Then of course Scotland beckoned and you joined what was a very vibrant clinical and academic setting, taking up a post on the scientific staff of the MRC Unit for Epidemiological Studies in Psychiatry.

The Edinburgh scene at that time was humming, as you may recall, David. You must remember it was the time when university departments were actually expanding and indeed so was the Medical Research Council's establishment. In Edinburgh the post of Director of the Unit and Head of the Department was jointly held by my friend Morris Carstairs, who showed outstanding administrative skills in integrating the work of the Royal Edinburgh Hospital and that of the Academic Department, while leaving the Unit largely to run its own course.

As you say, that was a time of expansion in psychiatry and certainly for a trainee in the 1970s it was a golden era with very robust clinical services led by Jim Affleck, then Physician Superintendent. together with three University Professors and two MRC Units. How had Edinburgh become so successful?

Probably by accident, as is usually the case. But perhaps to say that minimises the role of Morris Carstairs who was an extremely skilful and well-liked administrator able to make the very best of the opportunities that were opening up at the time. On the research side he was also fortunate in having with him Neil Kessel, whose contribution to studies of primary care and to what is now termed parasuicide have never been fully appreciated.

We have seen you working in part as a pure scientist when in Rome, taking an interest in social aspects of psychiatry while in Chichester and having a little sympathy at least for psychotherapeutic approaches. From such an eclectic background, how did the three main strands of Edinburgh MRC interests develop. those of suicide and parasuicide, alcohol and other dependence problems, and depressive illness particularly in its social context?

The parasuicide theme had really been set up by Neil Kessel. We had at that time an excellent clinical service in Edinburgh for selfpoisoning, one which alas has disappeared under the recent improvements introduced into the NHS. It was also an ideal research base and Neil had opened up the subject from an academic point of view so it was a natural progression to pick up and extend the work he had already done. The work on suicide came as a corollary to this although the problems are very different. Alcoholism was something of a novelty as far as the Unit was concerned but it poses all kinds of important issues which ramify well beyond its own field. We were fortunate in having with us Martin Plant, now Professor Plant, who still runs a very active research group in the alcohol field. The third line you mentioned, that of depression in women I suppose arose out of interest in George Brown's work on the effect of life events. We were intrigued by his findings and set out to investigate the same area. The aspect of it that interested me personally most was the possible effects of low selfesteem in women, which did emerge as important in relation to depressive illness but in a rather different way from that initially supposed. Of course, such progress as we made in these three areas was largely due to colleagues such as Jack Ingham, Paul Surtees, John Duffy, Patrick Miller and so many others with whom I had what was, for me at least, a happy working relationship over many years.

And all this, presumably, was based on an epidemiological approach?

Yes, but in order to use epidemiology to its full potential, which is to test hypotheses, you often need to venture well beyond survey work and the like. There are first the detailed clinical 
studies that are often necessary to improve the definition of the conditions you are interested in. Equally or even more important are sociological enquiries to clarify the social characteristics of the population subgroups you want to investigate. It is there that creativity usually arises; new hypotheses generally spring from new ways of thinking about social processes and what it means in people's lives to occupy a particular niche in the social structure - including their immediate interpersonal context as well as the larger scene.

After 27 years with the MRC what can you say about its place in psychiatric research?

As an organisation the MRC is obviously a major national asset and it is a fine thing to have the possibility of a career in full-time research with tolerable assurance that one is going to continue to eat. On the other hand, there are curious aspects about it as an organisation. One that impressed me early on was that out of the large number of Units, which at one time I think numbered about 80 , there was an enormous diversity of style. Some were, and still are, run as military corps with the Director giving orders to the subservient troops who then do precisely as they are told. Others incline towards the chaotic with everybody doing their own thing, which of course loses the advantage of having a Unit. A fellow Director and I once tried to prompt the MRC to undertake some sort of investigation into the optimum style of research management. The response was a loud yawn. Another odd feature is a curious lack of reciprocity between the organisation's headquarters and its peripheral staff. The MRC itself has a remit which inter alia is to promote medical research. To do this it is totally dependent upon the research community, and one might have supposed that there was a sense of mutual obligation between the two. In fact, however, the attitude of headquarters towards its scientific staff is that of a rather irritable nanny. You are told off if you misbehave in the slightest way as regards administrative matters while with scientific questions there seems to be no-one there to listen if you want to raise issues of scientific policy within a particular field. I have more often been amused than irritated by this peculiarly one-sided dialogue, though it may not sound like it, and I am certainly not saying that they are bad employers.

We can follow that one with a two-part question how might psychiatric research be better organised and what would you see as the main areas to be addressed?

I don't think I have any constructive comments to offer about the MRC organisation per se, the framework seems to me reasonably sound. I would only ask for more of a two-way flow of information and the occasional use of the phrase "Thank you". As for future research I think that a balance is required between what remain as the continuing problems and enigmas of psychiatry on the one hand, and on the other, what the new research opportunities have to offer. At the moment we are seeing a dramatic leap forward on the biological side which of course is entirely to be applauded. The danger is that it leads us to neglect the social and psychological aspects of psychiatry, which are equally important. I believe it is essential for all organisations like the MRC and for academic departments too to try and retain some sense of balance. Then beyond all this is the question of our total national investment in research and the importance - or lack thereof - we attach to it. I believe that the NHS, for example, spends less that $1 \%$ of its budget on research, including health service research which is presumably central to its development. Any large corporation which spent such a miserly proportion of its revenue on research and development would deservedly collapse within a year.

Research in psychotherapy probably offers the greatest methodological challenge. Can you enlarge a little on your interest in this field and upon how research might be promoted?

The research issues in psychotherapy are immensely complex and I don't think we have yet clarified them sufficiently to make any very rapid progress. At present we have to describe explorations in that area in terms of metaphors which do not as yet lend themselves to scientific formulation, though that could change if therapists were to devote more attention to process rather than concentrating so exclusively on therapeutic outcome. I do, however, deplore the increasing neglect of psychotherapy. It is important not only as a specialty but also as the best way to 
equip our trainees with the basic interpersonal skills they will certainly require whatever other kinds of therapy they elect to use. I still retain some interest in psychoanalysis, not as a scientific discipline-indeed I changed my mind about entering that field at quite an early stage - but because it requires the therapist to get as close as possible to the phenomenology of distress and what the patient actually experiences in the context of his own life story.

You maintained very active interests outside Edinburgh throughout your time with the MRC there. What stand out as particularly enyoyable or productive?

One of the experiences I found particularly interesting was the establishment of the Alcohol Education and Research Council. This was initiated in 1982 and was unusual in consisting of a group of people awarding research grants who for the most part were not research experts. This introduced a note of rugged common-sense into project assessment which is often sadly lacking and it worked surprisingly well. I also enjoyed many of the contacts through the University of Edinburgh, particularly the setting up of the School of Epistemics or what is now called Cognitive Science. This provided a chance to meet people from subjects including neuroscience, linguistics, psychology, zoology and philosophy, all of whom had a common interest in the problems of how we understand each other and what words like 'meaning' actually mean. Then, apart from international organisations, there have been the usual involvements with government bodies, chiefly those linked to the Scottish Office. These have convinced me, by the way, of the advantages of working in a comparatively small country like Scotland where the people on committees are also likely to interact in reality.

You always seem to have been in equal measure a doer and $a$ thinker, a huge volume of research came out of the MRC Unit yet those who know you personally probably value most your determination to think clearly and we have touched on this already with your interest in psychoanalysis. And I know your interest in philosophy continues actively with your involvement in the Scottish Division Special Interest Group. Can you enlarge upon that interest and its overlap with psychiatry?

Philosophy is a very curious subject. It contains no facts, at least none that belong to its own special province. But it does help to clarify one's thinking, especially about one's assumptions which are at least as important in psychiatry as in any other area, and it suggests that in the end one knows far less than one thinks one does.

That is a typically modest reply. What can we learn or know, however small, and where particularly do your philosophical interests lie?

Not particularly in metaphysics which I think is a frivolous subject. The areas which interest me most are the philosophy of science, which indeed every practising scientist of any kind needs to give some attention to, and then more recently, the field of aesthetics. I am fascinated by metaphor, particularly as used in literature but also in science and philosophy. I am hoping to do some work in that field in the near future.

You have mentioned metaphor both as a paradigm for science and for philosophy but of course it is most familiar to us in literature. Can you explain the commonality of metaphor in these different areas and where your particular interests lie in these fields?

What is common between all those areas is the sense of analogy. It seems that in all subjects we advance by saying 'this' is in some ways like 'that' and then enquiring if the similarity holds in other respects, and if so which? The ultimate extension of this I believe is to be found not so much in science or philosophy as in poetry, which has always interested me greatly. To digress slightly, there has been a certain amount of discussion over recent years as to whether trainee psychiatrists should be familiar with the main works in the literary canon. The answer of course is yes, because everybody should broaden their cultural horizon and appreciate the importance of sensitive discrimination. But I think it's a radical error to suppose that literature is the same kind of thing as science, to imagine that a textbook of psychology is trying to do the same thing as a novel or a poem. It is particularly dangerous when the two become confused, and I think a great deal of clarification is still required between the appropriate roles of the scientist and the writer. 
I understand that as part of your extensive list of publications two volumes of poetry are included - is there more to come?

A third is in preparation but I must admit that the juices flow more slowly as anno domini creeps up.

It strikes me that what research, philosophy and poetry all share is having some time to reflect, to think and to feel. But as clinicians we rarely find such opportunity in the hurly-burly of practice.

That's right. The clinician is paid by society to do the best he can with the knowledge he has. The point I was perhaps making was that we are unlikely to make much progress in the care we give our patients unless we can extend our knowledge of the disorders which afflict them. The greatest barrier at the present is our ignorance.

Perhaps you could tell us a little about your still very busy professional life even in retirement.

Actually the busiest aspect of it is not professional at all! It's remarkable how little time there is between the end of one's paid employment and just the end. It's very tempting to try and do everything that has been waiting on the back burner in the years that remain. Of course one won't succeed but what the heck, let's have a go!

\section{Seminars in Practical Forensic Psychiatry}

\section{Edited by Derek Chiswick \& Rosemary Cope}

Seminars in Practical Forensic Psychiatry is a concise account of the specialty from a strongly practical perspective. It systematically describes the relationship between psychiatric disorders and offending, with detailed discussion of the criminal justice system, court proceedings, mental health legislation, dangerousness, prison psychiatry, and civil issues. There are boxes summarising key points, illustrative case examples, and sample court reports. It is up-to-date, with references to the Reed Report, the Clunis Inquiry, supervision registers and recent legislation. Career guidance and a chapter on ethical issues are included. This book will be invaluable for general psychiatrists and for trainees in forensic psychiatry, as well as those other health and social work professionals having contact with mentally disordered offenders, and those who are part of the criminal justice system.

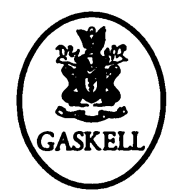

$\bullet £ 17.50 \bullet 359$ pp. $\bullet 1995 \bullet$ ISBN 0902241788

Available from bookshops and from the Publications Department, Royal College of Psychiatrists, 17 Belgrave Square, London SW1X 8PG (Tel. 0171-235 2351) 